\title{
New Objects, Old Age: \\ The Material Culture of Growing Old
}

https://doi.org/10.23991/ef.v44i0.59701

\begin{abstract}
Ageing and old age has become a phase of life occupied with new, often medical, devices; for instances blood pressure meters, medication, hearing aids, dentures and walking aids. These material objects are intended for surveillance, as well as to compensate or replace parts of the ageing body and its altered abilities. This article examines the material culture of growing old, using a phenomenological perspective as a point of departure and comprehending materiality as permeated with cultural norms and ideas that affect identity and agency. The article is based on two studies consisting of interviews and participant observation with persons between 66 and 93 years. The analysis focuses on how to understand the process that occurs when older people are faced with new objects associated with a certain age and with certain health conditions, how the medical materiality of old age is accepted, internalized, questioned or resisted, and how these medical objects fit in with everyday life.
\end{abstract}

\section{Introduction}

As the ageing process proceeds, everyday life may quickly become filled with new objects: medical devices such as blood pressure meters, medication, hearing aids, dentures and walking aids, just to mention a few. These material objects are intended for surveillance, as well as to compensate or replace parts of the ageing body and its altered abilities. Some of these things, such as a stick or a walking frame, even function as mundane but powerful symbols of old age.

Fitting new things into everyday life is nothing that is specific for older people. Throughout life, objects are added that need to be used and adjusted to existing routines. However, the difference between old age and other ages is that the items largely consist of medical objects. Indeed, similarities may exist with people of all ages who have certain types of chronic diseases or disabilities. Nevertheless, many of these medical objects are associated with old age, for example hearing aids and walking frames.

Even if ageing proceeds throughout life, the main group to be associated with the process of ageing is older people. Furthermore, old age and older individuals represent constructions that are regarded as different and deviating in comparison with younger people. ${ }^{1}$ Ageing stereotypes of decline, disease and dementia are ascribed to all older people (Katz 2009). Anne Leonora Blaakilde (2007) points out that even positive narratives about older people assume that ageing is something negative, synonymous to ill health. Positive narratives are about older people who are thought young for their age and who have an active lifestyle despite their age; their positive qualities are presented as individual, in contrast to negative qualities that are generalised and are considered valid for the entire age group.

The risk of ill health is particularly characteristic for constructions of the category of older 
people; this is linked to a higher degree of medicalisation (Kenen 1996). Medicalisation can be described as a societal process, which concerns a redefinition of health and what is considered healthy, but also the possibility of receiving more extensive care and treatment (Dumit 2012). Since the process of ageing is regarded as a period of reduced health and an increased risk for illness and ailment, this leads to the idea that ageing and its consequences should be treated in various ways. This also affects the objects that older people are surrounded by and that are offered by public medical services. These medical items involve expectations that older people should take responsibility for their own health and ageing and use these objects for that purpose. Such expectations are based in what Susan Wendell describes as societal disciplines of normality, with the object of forming and controlling people's bodies; this comes into effect through the myth that such control really is possible. Like other myths, it contains certain elements of truth, since we can control some bodily conditions, but far from all. (Wendell 1996.)

Research about ageing and old age is a multidisciplinary field that revolves around the body and embodiment, as well as subjectivity and identity, representation and the visual, and time and space (Twigg \& Martin 2015). Other themes are meaning-making processes, narratives and performativity with emphasis on old age as an identity marker (Swinnen \& Port 2012). Julia Twigg and Wendy Martin (2015) point out how focusing on identity and subjectivity highlight the lived experience of old age rather than external, objectifying and often medical accounts that present homogenizing and stereotypical images.

Objects and materiality, though, seem to be a topic of rare occurrence in research about ageing and old age; in fact, the term materiality is often used to refer to the embodied experience of ageing and old age (Swinnen \& Port 2012). Embodiment draws attention to the physical changes that are part of the ageing process and the way people manage them in their everyday life (Gilleard \& Higgs 2013). Embodied identities and the body as an active site for meaning-making are, for example, discussed by Twigg (2000). Using community care for older people as an empiric case, she demonstrates how body, time and place construct the identity of the older person in relation to the care work that is performed. Based on studies of older people with dementia, Pia Kontos maintains that subjectivity is embodied, emanating from the body's power of natural expression and socially and culturally acquired behavioural predispositions. Subjectivity and identity involve bodily dispositions and gestures, formed by social and cultural processes. (Kontos 2004; Kontos et al. 2017.) Consequently, as the ageing process is both social and biological, old age needs to be studied in conjunction with the ageing of bodies (Calasanti \& King 2005).

In my own research, the ageing body was the point of departure for exploring older people's experiences of ageing and old age, but the body also led me against its surrounding materiality. The older persons' stories turned out to be full of material objects; the participants' narratives of ageing and everyday life were based on how their ageing bodies related to mundane things. The ageing process was for instance "measured" by the individual through objects, meaning supervising how the body could handle everyday objects and routines. (Alftberg 2012.) Supervising and monitoring bodies through things was also a recurring theme in a study of older people's medications. The procedure of taking medicines included watching over every bodily symptom that occurred, and deriving them either to the medication or to the illness that was treated. (Alftberg 2015.)

Clearly, objects seem to be of significance for understanding ageing and old age, but we need to learn more. Research about older people and material objects primarily concerns the concept of downsizing, i.e. the reduction of objects that may occur in old age. This happens often through a move to another place, often an institutional setting, meaning leaving a larger dwelling than the one the older person move to. According to Catharina Nord (2013), the older persons bring with them different types of things; cherished objects, representations of who they were, and mundane objects. Apparently, the most important objects are the mundane things, preferred 
for the significance they have for the everyday life of the individual. On the other hand, JeanSebastien Marcoux (2001) points out that the reduction of objects when moving is not only about getting separated from one's possessions; it is also a matter of giving them to relatives or other potential recipients. Marcoux calls this a ritualized form of construction the self of the older person. Still, downsizing may occur without moving from one place to another. It can be a process of sorting out objects as a preparation for the end of life (Larsson Ranada \& Hagberg 2014). Even so, less is known about the opposite phenomenon: older people's increasing amount of objects such as assistive technology and medical items connected to old age.

Material culture captures the capacity of objects to affect people's minds, emotions and actions (Miller 2005). It suggests that things cannot be regarded as subjected to the will of the individual, but as something with the power to "interfere with who we are" (Mol 2008, 50). With the intention of further exploring the meaning of medical objects in old age, I will turn to phenomenology. According to Jonas Frykman and Nils Gilje (2003), a phenomenological perspective highlights how identity is lived and experienced. Phenomenology illuminates identity as not only involving ideas and conceptions in a reflexive project, but also including pre-reflexive actions and doings. This state of being prepared for action is intertwined with previous experiences of the individual, which in turn are dependent on the surroundings and the way the material culture is fashioned. (Frykman \& Gilje 2003.) Practices, action and situations are emphasised rather than conceptions, narrations and life trajectories; materiality and the surrounding world are regarded as active co-creators of practices and self-perception.

Thus, a phenomenological perspective opens up to individual experiences and accentuates the significance of material culture when it comes to people's meaning-making and identity work. Identity should be studied as an intertwinement between the individual and his/her surrounding world, assuming that subjectivity and materiality do not exclude but presuppose each other. In the same way as people provide meaning to everyday things, things endow people with meaning. (Frykman \& Gilje 2003; Frykman 2012.)

In this article, I will discuss what I would like to call the material culture of growing old, using a phenomenological perspective as a point of departure in order to study the intersection of materiality, identity and meaning. How can we understand the process that occurs when older people are faced with new objects associated with a certain age and with certain health conditions? In what way is this medical materiality of old age accepted, internalized, questioned or resisted? How do medical objects fit in with everyday life and everyday objects? The material culture of growing old certainly embraces other objects than medical and assistive devices, but the focus of interest here is medical items.

\section{Methods and Materials}

The article is based on two different studies involving ethnographic fieldwork consisting of interviews and participant observation with persons over 65 years of age, living in their ordinary homes in the south of Sweden (see Alftberg 2012 and 2015). The first study and conducted fieldwork aimed to explore lived experiences of ageing in relation to everyday life. Twelve persons between 80 and 90 years of age were interviewed, and participant observation was performed with two of them, focusing on their daily activities. To a great extent, the participants' narratives concerned material objects that they associated to ageing and old age. The second study concentrated on older peoples' views and experiences of their daily medication. Nine persons between 66 and 93 years were interviewed; during the interviews, they were also asked to show what kind of medication they had and where they kept them in their homes. With few exceptions, their medication had been prescribed some time after their retirement and had been used for at least five years.

Ethical considerations were a natural part of both studies. Respectful encounters with the participants included a sensitivity to their wishes and reactions, granting voluntariness to take part in 
the project as well as guaranteed confidentiality. The observations, in particular, were performed with responsiveness and awareness of the researcher's position to those researched upon. Also, consent from the Regional Ethical Review Board was obtained in both studies.

While these previous studies point towards the significance of everyday materiality in the narratives of growing old, I will here further explore and deepen the knowledge about the meaning of the new, medical objects that are connected with ageing and old age. The analysis was carried out by bringing together the empirical materials; taken as a whole, they were then scrutinized repeatedly to highlight and identify patterns. All meaningful text segments that related to medical objects in any way were underlined and organized into themes and finally analysed by the chosen theoretical perspective.

\section{Phenomenology and material objects}

When examining the material aspects of human existence, phenomenology enables a viewpoint of individuals as actors who are in constant readiness for whatever they come across. It accentuates identity and identity work as practices and experiences, and what happens in the encounters between people, places and objects. (Frykman 2012.)

The phenomenological perspective and the associated concept of intentionality point to the significance of materiality for the way people create meaning. The mind and consciousness are always directed towards something outside oneself. This is a consciousness about something, which is invariably oriented towards an object or a phenomenon (Bengtsson 2001, 27f). Intentionality is discussed by Sara Ahmed (2006), among others, she maintains that it should be understood as a direction or orientation. People are more oriented towards certain objects (as well as certain places or locations) than they are towards others. However, the objects we orient ourselves towards may on the other hand direct us or orient us in a particular way. Ahmed points out that some ways of orienting are more normative than oth- ers are. They are formed by cultural norms and ideas about what is regarded as normal or deviating. All directions and orientations start out from the basic vantage point of the individual; according to Ahmed, this is one's own body. This vantage point, together with objects that individuals orient themselves towards, however, is included in a social and cultural context. This governs which objects that are, or are understood to be, accessible.

Ahmed (2006) illustrates her thoughts by using empirical examples concerning sexuality and ethnicity. She problematises the vantage point of phenomenological philosophy, this invisible body on which orientation is based: it is male, white and heterosexual (and I would add middle-aged). Her reasoning thus adds the aspect of power to the phenomenological perspective that is also possible to apply to age and ageing. Ageing changes the ways of orientation considered possible and the objects that are understood to be accessible. An expression of this aspect of power is that objects may function as an extension of the individual, but they might also act repressively. Daniel Miller describes that objects, because they are taken for granted in their ordinariness, 'determine our expectations by setting the scene and ensuring normative behaviour, without being open to challenge. They determine what takes place to the extent that we are unconscious of their capacity to do so.' (Miller 2005, 5.)

Accordingly, the relationship between people and objects comes in different formations. An object may function as an extension of the body, but it can also direct the individual towards a social position, for example 'old age', a categorization that has mainly negative associations.

Old age is a fruitful way to highlight the intertwinement of people and objects because of the ageing body, where an altered body may give new meaning to things which are part of everyday life. Maurice Merleau-Ponty (2006) has developed such a phenomenological view of the body, maintaining that consciousness and body are closely intertwined. Body and consciousness are not two separate phenomena; they are two ways of describing the same thing. People do not have a body, they are their bodies. This is usually 
termed the lived body. It is not possible to separate the subject, the person, from that person's body (even if people sometimes do feel that their body is not part of themselves). We exist in the world as a body, with which we relate to the surrounding world. This vantage point means that when the body ages and changes, there is also a change in the way the individual regards and experiences their surrounding world.

In the following, I will discuss from a phenomenological perspective what happens when people are confronted with objects that they are expected to use because of their ageing bodies. To start with, I will present some examples of how things associated with ageing are received with resistance or with reluctant acceptance. Thereafter, I will bring attention to objects that are strongly associated with ageing and old age, namely medicines. Further, items associated with ageing, which are incorporated by the individual will be dealt with, and significant aspects in this context will be considered.

\section{Resistance and reluctant acceptance}

Resistance and reluctant acceptance are common approaches towards medical and assistive items. Here, the discussion will use the examples from two cases, Betty and Elsie, which have been chosen for the typical and articulated way they show resistance and/or reluctant acceptance.

Betty, 80 years old, has a chronic heart condition, which means that she sometimes needs to go to hospital for check-ups and treatment. This has continued for many years. Usually, she is admitted to a medical ward, but the last time she was in hospital she was placed in a geriatric ward. 'I really don't know why they did that' she says shaking her head. She is noticeably surprised by being placed in a ward intended particularly for the care of older people. Since her symptoms are the same as previously and she needed the same treatment as earlier, she does not understand why she was taken into a ward, other than the one she was used to.

Betty also mentions that on the same occasion, the doctor gave her a blood pressure moni- tor to take home. It is still unpacked; it is standing beside her bed in a white cardboard box. Betty says she does not use the monitor. She has even lent the battery to her neighbour. She says that the doctor laughed when he asked her on the telephone about her morning blood pressure, and when she said that she did not know, since the neighbour had needed to borrow the battery.

There are several other things lying on Betty's bedside table apart from the blood pressure monitor; a remote control for the television hanging on the wall opposite the bed, a telephone, books, travel catalogues, an atlas and a magnifying glass. Betty picks up the atlas and says she wanted to look up Thailand, 'my son is there again'. It is my favourite book, she explains. Travelling has always been an important part of Betty's life. She says that she still has the habit of collecting travel catalogues at travel agencies, just to lie in bed looking at them; she enjoys leafing through the catalogues.

All the things by Betty's bedside can be regarded as an extension of her, contributing to the creation of her as a subject - except the blood pressure monitor. Contrary to the other things beside the bed, it is not part of Betty's life. The monitor does not enable entwinement between body and world, rather, it problematises the relation between her body and the surrounding world. The monitor does not fit into her life, since it makes her into something she does not identify herself with, somebody who is old and infirm. Yet, even in its unopened package, the blood pressure monitor is capable of affecting Betty. By its mere existence, it creates a relation to her. You could say that it opens the door to a world that Betty is not prepared to become part of. It directs Betty towards ageing and gives her an identity as an old person (cf. Ahmed 2006). Nevertheless, in her resistance, she uses this identity when she puts on the part of the muddled old lady, who makes the doctor laugh indulgently.

Elsie, 90 years old, provides a further example of difficulties in accepting and using objects associated with ageing and old age. She has difficulties in walking, particularly outdoors. She has now decided to ask for a walking frame on wheels next time she visits the doctor. 'I have been fighting 
against it, it is a bit like giving up, getting a walking frame' she says with a light laugh. 'A friend of mine and my sister both say that it is ever so good, but. . ' Elsie falls silent. She knows that a walking frame would make life easier, but at the same time, she feels that getting one would mean giving something up. The walking frame, an object that is largely regarded as the essence of old age, ascribes Elsie an identity as 'old', including everything that is associated with this category.

The walking frame is an object associated with reduced abilities occurring in old age; the use of one is understood more as a necessity than free choice. Getting a walking frame or a blood pressure monitor means incorporating objects into life, and into what is understood as 'I', which leads to a change in the individual and this person's identity. This is what Elsie describes as 'giving up'. When the thing is incorporated, no matter whether it was desired or used unwillingly, it creates a new perspective of who I am and of the world surrounding me (Merleau-Ponty 2006). Such a change is not just dependent on the intertwining between body and object; it also depends on cultural norms and ideas with which the object is associated (Ahmed 2006). Even before there is a bodily relation, in the sense that the individual handles and incorporates the object as part of the body (or the body as part of the object), the materiality is capable of showing a potential perspective of the world (Miller 2005). Whether or not the world is experienced in the way you expected when the new object is actually used, is an open question. Perhaps it changes in an unexpected way because of the intertwinement between body and object. Perhaps Elsie will experience a greater ability to move around using the wheeled walking frame and feel more, not less, like herself again.

\section{Mundane medications}

Elsie often feels pain because of a previous illness, but she does not want to take painkillers. 'I don't want to take pills' she says. 'I struggle with the doctors, they try - if I took all the pills they recommend, I would ...' Elsie laughs and continues:
I say, I don't want them! "Yes but they are good, you understand, you should take them" and "of course, we cannot force you, but ...." [---] The way they try. I was given one kind and when I started taking them, they made me feel very strange, I had to phone the hospital in the middle of the night. I was wandering around ... I didn't know where I was and what I should do. So I stopped taking them. Why should I use such things? I feel well anyway.

Medication, particularly, is a matter that produces meaning in a special way, with reference to the Greek word farmakon. The term refers to the inherent ambivalence of medicine, since it might function as both a cure and a poison. Medicine cannot be said to be either healing or harmful; it is both at the same time. It can be constructed as harmful or as a cure depending on the situation it occurs in. (Derrida 2007.) Medicines are thus specifically connected to power, which is often described as magical, in the sense that the charged power exceeds the materiality of the object itself (Hansson 2007, 117). Kristofer Hansson (2007) shows that two different forces are at work when medication gains its quality of creating meaning. One is the ability to heal and change bodies and the other is that people believe in its effect and in the results. Both these forces are of significance in how people organise their lives, or rather how their days are organised around the medication and its magical power. Medicines are objects that can be moved spatially - individuals carry them around - but when the substance is consumed it is incorporated into the body and becomes part of it at the same time as it changes the body. (Hansson $2007,112 \mathrm{ff}$.)

Elsie's statement about pills should be regarded in the light of the ambivalent meaning of medicine, but also considering the concern expressed by the public as well as doctors about addiction, side effects and long-term effects, at least when medicine is being taken for a long period of time. This concern or fear is partly about effects on the body, but it mainly involves how it affects a person's personality and whether it might cause personality changes (Svenaeus 2008) ${ }^{3}$. Elsie does not recognise herself when she takes the tablets, and prefers not to take them; as she says, she 'feels well anyway'. 
Elsie's example is an exception, however, when it comes to medicines. In both of the studies based on interviews, medicines generally appear to be a natural part of ageing. There has been an overall increase in the use of medicines among older people. This is partly because new drugs have been introduced, but it is also due to the use of medicine when ageing and changes that are consequential to ageing are regarded as ailments that need to be treated (Conrad 2007). Medicines are particularly significant in ideas about ageing and the consequences of ageing as a state that needs treatment, since medication is a common form of treatment. This is especially clear in Elsie's example when she describes the attempts made by the medical service to urge her to use her medicines. The medication of older people often also entails the consumption of medicine with no final date. Medicines are generally prescribed for the rest of life, for example, substances to lower the blood pressure and anticoagulants. Accordingly, medication is a significant entity when discussing the material culture of growing old.

\section{A question of storage}

Medicines are thus considered a natural part of ageing and old age (Alftberg 2015). Incorporating medicines in everyday routines, however, can be problematic in view of how the medicine should be taken and stored. It is hence necessary to organise the daily consumption of medicines. One way is to use a pill organiser, a plastic box with a compartment for each day of the week and part of the day, in which the daily doses of pills can be portioned out. However, Robert 70 years old, mentions that his pill organiser is a thing, which he does not feel entirely comfortable with:

It actually took a while before I wanted to use this pill organiser, because it seemed a bit... well, a bit too elderly... I wasn't that old, not old enough to need one. And I don't really need it, but actually if you are travelling, it is... If you are going away for a fortnight or so perhaps, then you need to know that there is enough. So I used it [for travelling], and added an extra week, so I could bring enough for three weeks. And now I use it at home too. And it does work.

The pill organiser creates a direction or an orientation towards ageing and old age, which Robert has difficulties in identifying with. However, he chooses to use the pill organiser because of its practical function. Robert keeps the pill organiser in a small red toilet bag with a picture of Winniethe-Pooh. He says laughingly that his grandchild has expressed a wish for the toilet bag; Robert continues that he really does think that children and young people are a more suitable age category for the bag. It could be said that the youthful association of the bag might counteract and conceal the relation to old age.

Robert explains that he is not keen on letting the pill organiser or medicines stand around in sight:

I keep the pill organiser in a little bag, like that it can't be seen (Robert laughs). If you visit people and they have all their medicines standing in a row ... No that's not my... I want things, the packages are hidden nicely in the kitchen cupboard. You get them out when you fill up the pill organiser, otherwise, I don't think they should be left about.

It becomes evident in the empirical material that an important consideration is where to keep the medicine. The original packages of medicine are often placed together in a container, with the purpose of keeping the medication in a controlled and organised way in a specific place, often in the kitchen or bathroom. Another common occurrence is to transfer the doses of medicine from the original package to decorated boxes or other containers, not specifically pill organisers. These boxes or containers, with or without original packing, can be kept in view, or are concealed in various kinds of furniture such as cupboards or chests of drawers. There are several reasons for leaving the container in view, both aesthetic and practical. This is made clear when Carol, 76 years old, shows me her bathroom where she keeps her pills:

I have one of those little marble trinket boxes. I take them [the tablets] and pour them into the box, 
because it looks a bit nicer. Then I keep it on a shelf in my bathroom cabinet. There is no closed door or anything, it is in full view there, the little box. In the evening, I put a tablet on top of the lid. Then in the morning, I see it. I never go to bed without getting out my tablet.

The attractive little box functions as decoration and to make things feel more comfortable; 'it looks nicer' according to Carol. The box also reminds her of a routine that is to be done every morning, helping her to remember to take her medicine.

Another of the interviewed persons is Helen, 93 years old. She has a flat communicating with a residential home for older people, where there is a common dining room. Since she needs to take her medicines together with her lunch, she brings her pills to the dining room in a little oval porcelain trinket box with a lid of mother-of-pearl, which her daughter gave her. The box is small and neat, she says, and fits into her pocket. The decorated box is indeed charming. A similar sized box made of a material considered less aesthetic, such as plastic, could no doubt just as well have had the same practical function, for carrying a pill to the dining room. Porcelain as a material with its form and colour is often considered to heighten the aesthetic experience of objects in contrast to plastic, despite the everyday quality of both materials. This is apparent when Joan, 77 years old, takes her various medicines out of her kitchen cupboard and shows me two porcelain eggcups, white with a blue pattern, which she places on the table when laying it for breakfast. She puts the pills that she is to take with her meal in the eggcups. It is a kind of reminder for her, she says, so she can avoid taking a double dose. 'So I put the pills there, either in the evening before I go to bed, or in the morning. Then I have all the pills I need gathered there.' The decorated eggcups are included in a daily routine that we might almost call a ritualised laying of the table for a meal.

The decorated porcelain containers appear to function in the same way as a proper pill organiser; they are a reminder to take the daily dose of medicine correctly. Nevertheless, the aestheti- cally attractive containers create a more homely and comfortable feeling about the medication. When the medicines are kept in decorated boxes and containers, the association of the pills to health care, medication and in this case ageing can be concealed or lessened. In the words of Ahmed (2006), the medication can be redirected; it is reoriented to home life and everyday routines. In such a way, they are more easily incorporated as part of the individual. The significance of home facilitates this reorientation; home has the ability to transform the meaning of objects (Miller 2001). Simultaneously, a home can be regarded as created by the objects that are present and the way they are treated (Young 2005). The storage and transfer of packages, boxes and pills at home creates new meaning to older people's medicine.

\section{Dwelling through things}

The reorientation that occurs therefore points to the way things are intertwined with places. Objects cannot be studied isolated from the people who use them, nor can they be studied separate from their surroundings. In the case of medication, the medicines are associated with certain rooms; the kitchen, where breakfast is eaten with the morning pills, or the bathroom as in Carol's example above. Robert points out that he formerly kept his medicine in the bathroom, to make it easier to remember at the same time as he brushed his teeth in the evening. 'I had learnt that I had the evening medicine in the bathroom while I brushed my teeth. That made it quite easy to remember.' Things and places are connected to become memory markers, which is particularly noticeable in 70-year-old Margret's case. She mentions that she keeps her insulin in two different places. The 'dinner-dose' is taken around her dinnertime at six o'clock in the evening and is kept in the bathroom downstairs, while the dose to be taken at bedtime is kept in the bathroom upstairs near her bedroom. The two bathrooms on different floors of the house function as spatial reminders for each dose of the insulin. 
In this context, the rooms become what Peter Danholt and Henriette Langstrup call enabling places. 'These places are more than mere locations - they are allies that help weave medication into the fabric of everyday life in the home, as both material objects and as activities' (2012, 524). Danholt and Langstrup focus on how places and objects interact to create everyday routines. However, objects and places also interact spatially when objects become an extension of a person's body and of herself. Ahmed discusses that the direction of individuals, the state of being oriented, also means that they feel at home in the world and part of it. The way things and places are intertwined with one's body is so much taken for granted that it might be difficult to distinguish 'where one's body ends and the world begins' (Ahmed 2006, 134). In the description above of Betty and the things on her bedside table in her bedroom, we see that this is such a place, where body and surrounding world become intertwined. Through the objects, humans extend their bodies spatially and thereby themselves, in order to reach a position of acting, and ageing, subjects.

According to Otto Friedrich Bollnow (2011), space is part of human existence. In the same way as for objects, meaning is created in the relationship between individuals and place; places can shape us in the same way as we can shape places. The difference is that the relationship to objects is characterised by intentionality, while the relationship between humans, places and space is instead formed by dwelling, that is to say, the way we live and dwell in the world. The concept of dwelling is used in the sense of feeling at home in a particular place, rather than as localisation in general. Bollnow states that this particular place is (usually) our home. The house, the flat, or wherever we live, becomes our home because we dwell there. At the same time, we strive to create a feeling of home. Our home, Bollnow continues, is the essential foundation for how we structure places and spatiality. When people experience and assess the content of other places and the distance to them, they start out from their own homes. Home is the place we start out from and to which we return.
Bollnow (2011) maintains that the feeling of home is partly created through furniture and things that reflect the inhabitant's personality and history. In practice, the feeling of home or dwelling is achieved in different ways, for example, when Helen uses a decorated box, given to her by her daughter, to keep her pills in. In Betty's example, we see it in her habit of lying in bed watching TV, or looking through travel catalogues, surrounded by objects that are significant for her (as well as a blood pressure monitor in its original package). Bollnow also writes that the house or home is our basic vantage point, which he terms the zero point. A person's bed is the corresponding place inside the home, it is the absolute zero point. That is where individuals screen themselves off from the surrounding world, during sleep. Bollnow $(2011,156)$ mentions the kitchen table as an important point too. Furniture and places like this constitute the importance of home in concentrated form.

If Betty's place is in bed, Elsie's place is at the kitchen table. Elsie explains that this is where she mostly sits during the daytime. The room is long and narrow with walls in a light shade of colour. A bar counter divides the room into a part for cooking and a place for meals. The round white kitchen table with two chairs is placed beside one of the windows. On the wall beside the table, there are two small shelves, with newspapers, magazines and a radio. A mug filled with pens and pencils is standing on the table together with a pair of glasses and a jar of medicine. Elsie says that she usually listens to the radio, reads the paper and does crosswords. She also has a good view of the street outside. This is similar to Betty's place in bed, a specific place with significant things that are used regularly. This is the context in which we should regard new objects that are introduced due to ageing. Some objects are rejected and ignored, while others are accepted and are incorporated, becoming a part of the individual and of home. An important point when things are incorporated is that these medical objects can be reoriented through everyday routines, places or with the help of other things. 


\section{Conclusion: A material culture of growing old}

In this article, I have explored the process of managing new objects associated with a certain age and with certain health conditions. I have discussed how medical items of old age are accepted, internalized, questioned or resisted, and how they fit in with everyday life and everyday objects. In order to deepen the knowledge of ageing and old age, the significance of materiality is an important aspect to take into consideration. Viewing identities and subjectivities as embodied is not enough; the material dimension of human existence and meaning-making should be included to contribute to a richer understanding.

Previous research has studied the reduction of objects in old age, but as I have argued here, old age is also about obtaining objects, which has subsequent consequences for identity and meaning. Ageing involves the introduction of many new things in everyday life. Of course, incorporation of new objects into ordinary routines is not specific for older people, it occurs throughout life. New objects are transformed from being visible and consciously thought of, to become invisible and taken for granted; gradually they become a natural extension of the body in everyday life. Objects associated with ageing, on the other hand, are intended to compensate, complement and replace parts of the ageing body that has changed and does not work as it did previously. These medical aids also have a function of monitoring and surveillance of the body. This article displays how these new things appear to have the ability to categorise individuals. The objects are hindrances in people's direction, redirecting them and forcing them to reorient themselves. Material objects have the power to ascribe the individual an identity as 'old', due to the association of the object to old age.

Which actions are then offered to older people as users of objects and creators of meaning? In the relationship between person and object, there is space for resistance; quite simply, by not using the object. The things still require an attitude of some kind - for instance, the active choice of not using a blood pressure monitor - because of expectations that are brought with the object into the home of the older person. To accept and make use of an unwanted object instead, needs (at least to begin with) a redefinition of one's selfimage and identity, and such a process might be more or less dramatic.

Medical objects that are associated with ageing might also be regarded as natural or self-evident. They are taken for granted and considered part of the course of life; that is how things are when you get old. The incorporation of these things might not be particularly difficult when it comes to identity or self-image, but it might still involve certain complications. How does the new object become part of already existing habits and routines? How do you create new habits? The findings show that one way of reorienting the objects is to make them suit everyday procedures. They can be transformed in various ways, for example, they can be made more homely and personal as in the case of medicines placed in decorated porcelain boxes. This highlights the mutual influence between material objects and individual identity.

Objects are also intertwined with the places where they occur, influencing the way people dwell in the world. Objects and places can then be interwoven with time. Altogether, this might function as a memory marker, a point around which everyday routines can revolve. Home has a particular significance in its capacity to reorient objects; the rooms of home can be interwoven with things and body, which creates a feeling of belonging.

Objects can open up the world and provide people with the ability to do things, in the same way as they can hinder and repress. In a context of ageing and old age, objects can be offered for use that emphasise the right way to age; these may be medical objects that encourage the monitoring of an ageing body. Users of these objects can be said to internalise the norms involved in the thing and the values that are associated with it. As a result, the material culture of growing old may entail unarticulated but extensive obligations concerning ageing in accordance with the expectations of society. Individuals who do not use the objects in the prescribed way risk moral and social sanc- 
tions when they are considered not to fulfil their expected responsibilities. The material culture of growing old thus involves orientation consisting of cultural norms and ideas that affect the identity of older people and their agency.

\section{Acknowledgements}

The author is grateful to the anonymous reviewers for their helpful comments and valuable advice on the manuscript.

\section{NOTES}

1 Age is not just a numeral indicating how old somebody is; it should be regarded as a social order, a basic condition in the arrangement of society. Age is also a way to categorise people by defining similarities and differences, thus creating hierarchies and positions of power. Similar to categories such as gender, class, ethnicity and functional ability, age constitutes a principle for creating social order and relations of power in society. Adult and middle-aged people tend to become an implicit measure, with which other ages - childhood, youth and old age - are compared. Middle-aged people thus come to be the norm and other ages deviate from this. Consequently, adult life is ascribed higher status and a better position of power than, for example, old age. Each age is attributed different norms, ideas and expectations. (Närvänen 2004; Krekula 2009.)

2 Michel Foucault uses the concept of biopower to describe how this disciplination developed as an occurrence in modern society with the purpose of controlling and governing the population (Foucault 1995, 1990).

3 Antidepressant medicines are particularly considered to lead to a transformation in an individual's personality and self-knowledge. Such a change is regarded as negative if it is due to medication, which is thought to be an artificial way of increasing self-knowledge. On the other hand, a transformation that has arisen through therapy is regarded as authentic and the right way to self-development (Svenaeus 2008).

\section{REFERENCES}

Ahmed, Sara. 2006. Queer Phenomenology. Orientations, Objects, Others. Durham/London: Duke University Press.

Alftberg, Åsa. 2012. Vad är det att åldras? En etnologisk studie av åldrande, kropp och materialitet. Lund: Lunds universitet.

Alftberg, Åsa. 2015. "Mellan vanor och faror. Äldre människors bruk av läkemedel." Working Papers in Medical Humanities 1 (1): 1-37.

Bengtsson, Jan. 2001. Sammanflätningar. Husserls och Merleau-Pontys fenomenologi. Göteborg: Daidalos.

Blaakilde, Anne Leonora. 2007. "Löper tiden från Kronos? Om kronologiseringens betydelse för föreställningar om ålder." In Åldrandets betydelser, edited by LarsEric Jönsson, and Susanne Lundin, 25-51. Lund: Studentlitteratur.

Bollnow, Otto Friedrich. 2011. Human space. London: Hyphen press.

Calasanti, Toni, and King, Neal. 2005. "Firming the Floppy Penis: Age, Class, and Gender Relations in the Lives of Old Men." Men and Masculinities 8 (3): 3-23. https:// doi.org/10.1177/1097184X04268799

Conrad, Peter. 2007. The medicalization of society. On the transformation of human conditions into treatable disorders. Baltimore: Johns Hopkins University Press.
Danholt, Peter, and Langstrup, Henriette. 2012. "Medication as Infrastructure: Decentering Self-care." Culture Unbound: Journal of Current Cultural Research 4: (3): 513 532. https://doi.org/10.3384/cu.2000.1525.124513

Derrida, Jacques. 2007. Apoteket. Stockholm: Kykeon.

Dumit, Joseph. 2012. Drugs for Life. How Pharmaceutical Companies Define Our Health. Durham/London: Duke University Press.

Foucault, Michel. 1990. The History of Sexuality, Vol. 1: An Introduction. New York: Vintage Books.

Foucault, Michel. 1995. Discipline and Punish: The Birth of the Prison. New York: Random House USA Inc.

Frykman, Jonas. 2012. Berörd. Plats, kropp och ting i fenomenologisk kulturanalys. Stockholm: Carlsson Bokförlag.

Frykman, Jonas, and Gilje, Nils. 2003. "Being There. An Introduction." In Being There. New Perspectives on Phenomenology and the Analysis of Culture, edited by Jonas Frykman, and Nils Gilje, 7-51. Lund: Nordic Academic Press.

Gilleard, Chris and Higgs, Paul. 2013. Ageing, corporeality and embodiment. London: Anthem Press.

Hansson, Kristofer. 2007. I ett andetag. En kulturanalys av astma som begränsning och möjlighet. Stockholm: Critical Ethnography Press. 
Katz, Stephen. 2009. "Introduction." In Cultural aging: life course, lifestyle, and senior worlds, edited by Stephen Katz, 11-20. North York, Ont.: University of Toronto Press.

Kenen, Regina. 1996. "The at-risk health status and technology: a diagnostic invitation and the "gift" of knowing." Social Science \& Medicine 42 (11): 1545-1553. https://doi.org/10.1016/0277-9536(95)00248-0

Kontos, Pia. 2004. "Ethnographic Reflections on Selfhood, Embodiment and Alzheimer's Disease." Ageing \& Society 24 (6): 829-849. https://doi.org/10.1017/ S0144686X04002375

Kontos, Pia, Miller, Karen-Lee, Mitchell, Gail Joyce, and Stirling-Twist, Jan. 2017. "Presence redefined: The reciprocal nature of engagement between elder-clowns and persons with dementia." Dementia 16 (1): 46-66. https://doi.org/10.1177/1471301215580895.

Krekula, Clary. 2009. "Age coding - on age-based practices of Distinction." International Journal of Ageing and Later Life 4 (2): 7-31. https://doi.org/10.3384/ ijal.1652-8670.09427

Larsson Ranada, Åsa, and Hagberg, Jan-Erik. 2014. "All the things I have - Handling one's material room in old age." Journal of Aging Studies 31: 110-118. https:// doi.org/10.1016/j.jaging.2014.09.004

Marcoux, Jean-Sebastien. 2001. "The 'casser maison' ritual - Constructing the self by emptying the home." Journal of Material Culture 6 (2): 213-235.

Merleau-Ponty, Maurice. 2006. Phenomenology of Perception. London/New York: Routledge.

Miller, Daniel (ed.). 2001. Home Possessions. Material Culture behind Closed Doors. Oxford/New York: Berg.

Miller, Daniel. 2005. "Materiality: An Introduction." In Materiality, edited by Daniel Miller, 1-50. Durham/ London: Duke University Press.
Mol, Annemarie. 2008. The Logic of Care. Health and the problem of patient choice. London/New York: Routledge.

Nord, Catharina. 2013. "A day to be lived. Elderly people's possessions for everyday life in assisted living." Journal of Aging Studies 27 (2): 135-142. https://doi. org/10.1016/j.jaging.2012.12.002

Närvänen, Anna-Liisa. 2004. "Age, ageing and the life course." In Changing worlds and the ageing subject: dimensions in the study of ageing and later life, edited by Britt-Marie Öberg, Anna-Liisa Närvänen, Elisabet Näsman, and Erik Olsson, 65-80. Aldershot: Ashgate.

Svenaeus, Fredrik. 2007. "Phenomenology listens to Prozac: analyzing the SSRI revolution." In Medical technologies and the life world: the social construction of normality, edited by Sonja Olin-Lauritzen, and Lars-Christer Hydén, 164-183. London/New York: Routledge.

Svenaeus, Fredrik. 2008. Tabletter för känsliga själar. Den antidepressiva revolutionen. Nora: Nya Doxa.

Swinnen, Aagje and Port, Cynthia. 2012. "Aging, narrative and performance:

Essays from the humanities." International Journal of Ageing and Later Life 7 (2): 9-15. 1 https://doi. org/0.3384/ijal.1652-8670.1272a1

Twigg, Julia. 2000. Bathing. The Body and Community Care. London/New York: Routledge.

Twigg, Julia and Martin, Wendy. 2015. "The Challenge of Cultural Gerontology." The Gerontologist 55 (3): 353-359. https://doi.org/10.1093/geront/gnu061

Wendell, Susan. 1996. The Rejected Body. Feminist Philosophical Reflections on Disability. New York: Routledge.

Young, Iris Marion. 2005. On female body experience: "Throwing like a girl" and other essays. New York: Oxford University Press.

\section{KEYWORDS}

Materiality, ageing, phenomenology, medicalisation, older people's everyday life 